Research Article

\title{
Perbedaan Tingkat Pemahaman Pengetahuan pada Anak Tunarungu antara Penyuluhan Metode Komik dan Video
}

The Difference in Understanding between Comic and Video counseling method for Hearing Impairment Children

Likky Tiara Alphianti $^{1 *}$, Firda Tsani Aulia Rahma ${ }^{2}$

${ }^{1}$ Departemen Ilmu Kedokteran Gigi Anak, Fakultas Kedokteran dan Ilmu Kesehatan, Universitas Muhammadiyah Yogyakarta, Jalan Brawijaya Tamantirto Kasihan, Bantul, Yogyakarta, Indonesia.

${ }^{2}$ Prodi Kedokteran Gigi, Fakultas Kedokteran dan Ilmu Kesehatan, Universitas Muhammadiyah Yogyakarta, Jalan Brawijaya Tamantirto

Kasihan, Bantul, Yogyakarta, Indonesia.

Received date: March $02^{\text {nd }}, 2021$; reviewed date: April 04 $4^{\text {th }}, 2021$; revised date: April 24 $4^{\text {th }}, 2021$; accepted date: May $05^{\text {th }}, 2021$

DOI : $10.18196 /$ di.v10i1.11245

\begin{abstract}
Abstrak
Adanya hambatan pada proses berbicara dan berbahasa sehingga menyebabkan kesulitan dalam berkomunikasi merupakan hal yang dialami oleh anak tuna rungu. Indera penglihatan menjadi hal penting yang dapat dimanfaatkan dengan optimal untuk berkomunikasi oleh anak tuna rungu. Tujuan dari penelitian ini adalah untuk mengungkapkan ada tidaknya perbedaan tingkat pemahaman anak tuna rungu terhadap kesehatan gigi-mulut setelah diberikan penyuluhan antara 2 metode, yaitu komik dan video. Desain penelitian yang digunakan adalah eksperimental kuasi. Sampel dipilih dengan teknik total sampling pada siswa tuna rungu (10-16 tahun) di SLBN 1 Bantul sesuai kriteria penelitian $(\mathrm{N}=14)$. Subjek pada kelompok 1 diberikan penyuluhan dengan metode komik dan kelompok 2 metode video. Data penelitian ini merupakan hasil penilaian kuesioner sebelum dan sesudah penyuluhan. Hasil uji statistik Wilcoxon menunjukkan bahwa baik pada kelompok 1 dan 2 tidak ada perbedaan antara pre-test dan post-test ( $\mathrm{p}>0,05)$. Hasil uji Mann-Whitney didapatkan $p>0,05$, hal ini menunjukkan tidak terdapat perbedaan yang signifikan antara kedua kelompok. Kesimpulan pada penelitian ini adalah tidak terdapat perbedaan tingkat pemahaman terhadap kesehatan gigi dan mulut sebelum dan setelah pemberian penyuluhan antara metode komik dan video pada anak tuna rungu.
\end{abstract}

Kata Kunci : Anak; Komik; Penyuluhan; Tuna Rungu; Video

\begin{abstract}
Obstacles in the speaking and language process, causing delays and difficulties in matters related to communication, are some of the things experienced by hearing impairment children. The sense of sight was an important thing that can be used optimally for communication by hearing impairment children. The aims of this study was conducted to determine and assess whether there was a difference in the level of understanding of dental and oral health after being given counseling between the comic method and the video method for hearing impairment children. The design in this study used a Quasy Experimental with a Non-Randomized Control Group Pre-Test and Post-Test Design. The sampling technique used was the total sampling technique for hearing impairment children aged 10-16 years who attended SLBN 1 Bantul, then obtained a total of 14 subjects who met the research criteria. Group 1 was the subject who was given counseling using the comic method and group 2 was the video method. This research data was primary data from the results of questionnaire assessment before and after counceling. Based on the Wilcoxon test, it was found that in both groups 1 and 2 there was no difference between before and after counseling ( $p>0.05)$. The results of the Mann-Whitney test obtained a significance value/ $p$-value of 0.474 ( $p>0.05)$, this indicates that there was no significant difference between the
\end{abstract}

* Corresponding author : drg.likky@umy.ac.id 
two groups. In conclusion, there was no significant difference in the level of understanding towards dental and oral health after providing counseling between the video method and the comic method for hearing impairment children.

Keywords: Children; Comics; Counseling; Hearing Impairment; Videos

\section{PENDAHULUAN}

Kesehatan mulut adalah faktor penyokong persepsi sehat serta penunjang strategi dalam pembangunan nasional untuk mencapai pembangunan Indonesia sehat. ${ }^{1}$ Hasil Riset Kesehatan Dasar (Riskesdas) tahun 2013, permasalahan gigi-mulut di Indonesia meningkat dari tahun $2007 \mathrm{ke}$ 2013 sebesar $2,7 \%$, dan $25,2 \%$ problem gigi-mulut diderita anak usia 10-14 tahun. Berdasarkan data tahun 2019 dari Kementrian Kesehatan Republik Indonesia (Kemenkes RI), karies gigi terjadi pada 89\% anak Indonesia dibawah usia 12 tahun. Hal ini menggambarkan bahwa masyarakat Indonesia khususnya anak-anak masih kurang memiliki kesadaran dalam menjaga kesehatan gigi-mulut. $\stackrel{2}{\text { Rendahnya }}$ pengetahuan juga dapat menjadi salah satu penyebab tingginya prevalensi permasalahan dalam rongga mulut. $\frac{3}{}$

$$
\text { Usaha dalam meningkatkan }
$$

kesehatan gigi dan mulut dapat meliputi upaya peningkatan pengetahuan, baik meliputi promotif, preventif, kuratif, maupun rehabilitatif. Pengetahuan dapat menyebabkan perubahan sikap dan perilaku pada seorang individu yang berdampak pada kehidupan sehari-harinya. Upaya preventif salah satunya dengan memberikan penyuluhan, yaitu cara mempengaruhi perilaku manusia sehingga timbul keinginan mengubah perilaku menjadi lebih baik. ${ }^{4}$ Kurangnya pengetahuan akan kesehatan gigi-mulut menyebabkan sering kali permasalahan ini diabaikan. ${ }^{\frac{5}{}}$ Semakin baik pengetahuan, sikap dan perilaku terhadap pemeliharaan kebersihan gigi dan mulut maka akan semakin baik status kesehatan mulutnya. $\underline{6}$

Anak tuna rungu tergolong individu dengan kebutuhan khusus, dengan kata lain merupakan individu dengan ciri yang berbeda dari anak normal. Anak dengan kebutuhan khusus menunjukan karakteristik fisik, emosional dan intelektual yang berbeda dari anak normal. Kesehatan gigimulut pada anak ini lebih rendah dibandingkan dengan anak normal. ${ }^{7}$ Hal ini disebabkan karena kurangnya pengetahuan, perhatian, serta tindakan pencegahan terhadap masalah tersebut. ${ }^{8}$

Anak tuna rungu mengalami hambatan seperti keterlambatan dan kesulitan dalam komunikasi. Mereka dapat memanfaatkan indera penglihatan (visual) dan kemampuan motoriknya sebagai panduan dalam berkomunikasi. Mereka membutuhkan alat peraga untuk membantu memahami suatu materi atau dalam belajar. ${ }^{9}$

Media komunikasi visual dapat berupa gambaran bergerak seperti video animasi, film serta gambaran tidak bergerak, seperti komik, leaflet, poster, peta, boneka, dan bagan model. Video animasi dapat menjadi metode pendidikan kesehatan gigi yang menarik serta dapat disesuaikan dengan kebutuhan anak penderita tuna rungu yaitu lebih berfokus pada visualnya. ${ }^{10}$, 11 Penelitian menunjukkan bahwa media film/ video dapat meningkatkan pengetahuan dan sikap anak mengenai hidup sehat. ${ }^{12}$ Komik merupakan rangkaian gambar yang menampilkan cerita secara berurutan. Pesan yang terdapat dalam komik akan lebih mudah tersampaikan kepada orang yang membaca dikarenakan gambar-gambar tersebut dapat menstimulus persepsi pembacanya. ${ }^{13}$ Komik banyak digunakan sebagai media pembelajaran yang potensial dalam menyampaikan pesan pada anak-anak sekolah. $\underline{14}$

Anak usia 10-16 tahun, menurut aspek perkembangan kognitif termasuk dalam periode operasional konkret (7-12 tahun) dan periode operasional formal (di atas 12 tahun). Anak dalam periode operasional konkret, dimulai dengan anak dapat mempertimbangkan beberapa aspek 
dari suatu masalah untuk bisa memecahkannya dengan meningkatnya fungsi-fungsi indera anak dalam mengamati serta memperkuat pengalaman yang diperoleh sehingga mempengaruhi kemampuan anak dalam berpikir secara konkret. Periode operasional formal disebut juga sebagai masa propotional thinking, memiliki karakteristik pada kemampuan anak dalam berpikir secara logis. $\stackrel{11}{ }$ Penulis tertarik untuk mengkaji ada tidaknya perbedaan antara sebelum dengan sesudah penyuluhan dengan metode video dibandingkan dengan metode komik terkait tingkat pemahaman kesehatan gigi-mulut anak tuna rungu.

\section{MATERIAL DAN METODE}

Jenis penelitian ini menggunakan quasy experimental dengan non-randomized control group pre-test dan post-test design. Penelitian ini telah mendapatkan persetujuan dari Komite Etik Penelitian Fakultas Kedokteran dan Ilmu Kesehatan Universitas Muhammadiyah Yogyakarta dengan nomor: 588/EP-FKIK-UMY/XI/2018. Penelitian telah dilaksanakan pada tanggal 6 sampai 7 Februari 2019 pada anak dengan gangguan pendengaran usia 10-16 tahun di SLB Negeri 1 Bantul dengan menggunakan metode Nonprobability Sampling yaitu Total Sampling, dan didapatkan sebanyak 14 subjek yang sesuai dengan kriteria penelitian Informed consent diberikan sebagai persetujuan atau penolakan orangtua atau wali anak secara tertulis berisi kesediaannya untuk anak mengikuti kegiatan penelitian dari awal hingga selesai tanpa paksaan apapun. Kuesioner berisi pertanyaan seputar kesehatan gigi dan mulut digunakan sebagai alat ukur. Subjek dibedakan menjadi 2 kelompok, kelompok 1 pemberian penyuluhan dengan metode komik dan kelompok 2 dengan metode video. Data yang didapat pada penelitian ini merupakan data primer yang didapatkan langsung dari hasil kuesioner.

\section{HASIL}

Subjek dalam penelitian ini berjumlah 14 anak yang dibagi secara acak dalam dua kelompok dengan jumlah yang sama dan pada tiap kelompok dilakukan matching berdasarkan usia. Distribusi subjek berdasarkan jenis kelamin dan usia pada dapat dilihat dalam tabel 1 dan tabel 2.

Tabel 1. Distribusi karakteristik seluruh subjek berdasarkan jenis kelamin

\begin{tabular}{lll}
\hline & $\mathrm{n}$ & $(\%)$ \\
\hline Laki-Laki & 6 & $42,9 \%$ \\
Perempuan & 8 & $57,1 \%$ \\
Total & 14 & $100 \%$ \\
\hline
\end{tabular}

Tabel 1 menunjukan subjek penelitian lebih banyak terdiri dari anak perempuan $(57,1 \%)$ daripada anak laki-laki $(42,9 \%)$

Tabel 2. Distribusi karakteristik subjek pada tiap kelompok penelitian berdasarkan usia

\begin{tabular}{lll}
\hline Usia (tahun) & $\mathrm{n}$ & $(\%)$ \\
\hline 10 & 1 & $14,3 \%$ \\
11 & 3 & $42,9 \%$ \\
15 & 2 & $28,6 \%$ \\
16 & 1 & $14,3 \%$ \\
Total & 7 & $100 \%$ \\
\hline
\end{tabular}

Pada tabel 2 dapat dilihat bahwa baik kelompok 1 maupun 2 memiliki subjek dengan usia 10, 11, 15, dan 16 tahun secara berurutan sebanyak 1 anak $(14,3 \%), 3$ anak $(42,9 \%), 2$ anak $(28,6 \%)$, dan 1 anak $(14,3 \%)$.

Tabel 3. Distribusi Tingkat Pengetahuan Subjek Sebelum dan Sesudah Penyuluhan

\begin{tabular}{lcccc}
\hline & & Kelompok 1 & Kelompok 2 \\
Kategori & Pretest (n) & Posttest (n) & Pretest (n) & Posttest (n) \\
\hline Rendah & $42,86 \%(3)$ & $28,57 \%(2)$ & $28,57 \%(2)$ & $57,14 \%(4)$ \\
Sedang & $28,57 \%(2)$ & $57,14 \%(4)$ & $14,29 \%(1)$ & $28,57 \%(2)$ \\
Tinggi & $28,57 \%(2)$ & $14,29 \%(1)$ & $57,14 \%(4)$ & $14,29 \%(1)$ \\
Peningkatan & & $28,57 \%(2)$ & & $14,29 \%(1)$ \\
Nilai & & $57,14 \%(4)$ & & $42,86 \%(3)$ \\
Nilai Tetap & $14,29 \%(1)$ & & $42,86 \%(3)$ \\
Penurunan Nilai & & & & \\
\hline
\end{tabular}


Data tingkat pengetahuan subjek didapatkan dari hasil penilaian kuesioner sebelum dan sesudah penyuluhan pada setiap kelompok, yang dikategorikan menjadi: nilai rendah, sedang, tinggi, peningkatan nilai, nilai tetap dan penurunan nilai pada subjek. Distribusi data berupa kategori nilai kuesioner sebelum dan sesudah penyuluhan terdapat pada tabel 3 .

Tabel 3 menunjukkan bahwa peningkatan nilai pada subjek antara sebelum dan sesudah penyuluhan lebih banyak pada kelompok 1 (metode komik), sedangkan subjek yang mengalami penurunan nilai ditemui lebih banyak pada kelompok 2 (metode video). Subjek dengan nilai tetap lebih banyak pada kelompok 1 (komik).

Sesuai hasil uji homogenitas data yang menunjukkan bahwa distribusi data normal, maka uji Wilcoxon digunakan untuk mengetahui adanya perbedaan tingkat pemahaman antara sebelum dan sesudah penyuluhan dilakukan dengan yang dapat dilihat pada tabel 4 . kelompok dengan menggunakan uji MannWhitney (tabel 5).

Nilai signifikansi yang dihasilkan pada perbandingan nilai pre-test antara kedua kelompok adalah $p=0,948(p>0,05)$, sehingga menunjukkan bahwa sebelum penyuluhan, subjek pada kedua kelompok memiliki kemampuan yang sama (perbedaan tidak signifikan antara nilai pre-test pada kelompok I (metode komik) dan kelompok II (metode video).

Tabel 5. Hasil Uji Mann-Whitney Nilai Pre-test, Post-test, dan Selisih pada kelompok 1 dan 2

\begin{tabular}{lr}
\hline Variabel & $\begin{array}{r}\text { Asymp. Sig. (2- } \\
\text { tailed) }\end{array}$ \\
\hline $\begin{array}{l}\text { Nilai Pre-test Kelompok I } \\
\text { dan Kelompok II }\end{array}$ & 0,948 \\
$\begin{array}{l}\text { Nilai Post-test Kelompok I } \\
\text { dan Kelompok II }\end{array}$ & 0,307 \\
$\begin{array}{l}\text { Nilai Selisih Kelompok I } \\
\text { dan Kelompok II }\end{array}$ & 0,474
\end{tabular}

Perbandingan nilai post-test pada kedua kelompok, didapatkan nilai $p=0,307$ (p> 0,05), hal ini menunjukkan tidak

Tabel 4. Hasil Uji Wilcoxon Nilai Kuesioner Sebelum (Pre-test) dan Sesudah (Post-test) Penyuluhan pada Kelompok 1 dan Kelompok 2

\begin{tabular}{|c|c|c|c|c|c|c|c|}
\hline \multicolumn{4}{|c|}{ Kelompok 1} & \multicolumn{4}{|c|}{ Kelompok 2} \\
\hline & & $\mathrm{N}$ & $\begin{array}{c}\text { Asymp. Sig. } \\
\text { (2-tailed) }\end{array}$ & & & $\mathrm{N}$ & $\begin{array}{l}\text { Asymp. Sig. } \\
\text { (2-tailed) }\end{array}$ \\
\hline \multirow[t]{4}{*}{$\begin{array}{l}\text { Posttest- } \\
\text { Pretest }\end{array}$} & $\begin{array}{l}\text { Negative } \\
\text { ranks }\end{array}$ & $1^{\mathrm{a}}$ & \multirow{4}{*}{0,713} & $\begin{array}{l}\text { Posttest- } \\
\text { Pretest }\end{array}$ & $\begin{array}{c}\text { Negative } \\
\text { ranks }\end{array}$ & $4^{\mathrm{a}}$ & \multirow{4}{*}{0,671} \\
\hline & $\begin{array}{l}\text { Positive } \\
\text { ranks }\end{array}$ & $3^{b}$ & & & $\begin{array}{l}\text { Positive } \\
\text { rank }\end{array}$ & $2^{\mathrm{b}}$ & \\
\hline & Ties & $3^{\mathrm{c}}$ & & & Ties & $1^{\mathrm{c}}$ & \\
\hline & Total & 7 & & & Total & 7 & \\
\hline
\end{tabular}

Berdasarkan tabel 4, hasil uji Wilcoxon menunjukkan bahwa nilai $p$ pada kelompok 1 (metode komik) adalah 0,713 $(p>0,05)$ dan nilai $p=0,617(p>0,05)$ pada kelompok 2 (metode video), sehingga dapat disimpulan bahwa tidak ada perbedaan pada tingkat pengetahuan kesehatan gigi dan mulut antara sebelum (pretest) dan sesudah (posttest) dilakukan penyuluhan.

Analisis data dilanjutkan dengan membandingkan nilai pre-test, post-test, dan selisih (posttest dikurang pretest) disetiap terdapat perbedaan yang signifikan antara kelompok 1 (metode komik) dan kelompok 2 (metode video). Perbedaan peningkatan pengetahuan (selisih dari pre-test dan posttest) antara kedua kelompok didapatkan $p=$ $0,474(p>0,05)$ sehingga antara kedua kelompok penelitian perbedaannya tidak signifikan.

\section{PEMBAHASAN}

Teori Piaget mengatakan anak perempuan lebih unggul dalam kecermatan, ketelitian, dan kecepatan berpikir, 
sedangkan anak laki-laki memilik keunggulan dalam hal logika. $\underline{15}$

Sejalan dengan penelitian ini, hasil penelitian terdahulu menunjukkan bahwa anak tuna rungu dalam proses pemahaman membaca akan lebih lambat dari anak normal, sehingga proses pemahaman melalui gambar dan tulisan seperti dalam komik maupun video animasi butuh waktu yang lebih lama karena harus diutarakan secara nyata melalui gerak atau secara langsung dengan bahasa yang mudah dimengerti oleh mereka. ${ }^{16}$ Hal tersebut sebagai salah satu penyebab metode komik maupun video animasi kurang dapat memberikan pengaruh lebih terhadap pengetahuan responden dalam penelitian.

Perubahan pengetahuan pada responden yang diberikan penyuluhan metode komik lebih memberikan perbedaan namun tidak signifikan secara statistik, yaitu dengan 1 anak yang mengalami penurunan pengetahuan dan 2 anak yang mengalami peningkatan pemahaman. Sejalan dengan penelitian ini, hasil penelitian lain menemukan bahwa komik dapat efektif dalam meningkatkan pengetahuan siswa dan dapat digunakan sebagai media promosi kesehatan. $\underline{17}$

Kelebihan media komik dibandingkan dengan media lain yaitu dapat sebagai motivasi belajar, membantu dalam mengembangkan kemampuan berbahasa, pesan lebih mudah tersampaikan kepada pembaca. Kelemahan media komik, gambar dalam komik yang menerangkan cerita menjadikan anak kurang minat dalam membaca teks karena teks hanya sebagai pelengkap gambar. Oleh karena itu, peran guru atau pendamping sangat penting untuk membantu mengarahkan anak untuk memahami isi komik agar maksud dari materi yang disampaikan dapat dipahami sepenuhnya. $\underline{18}, \underline{19}$

Metode video animasi pada penelitian ini kurang dapat memberikan perbedaan yang signifikan terhadap pengetahun kesehatan gigi dan mulut responden, dilihat dari penurunan pengetahuan yang terjadi pada 3 responden dan hanya 1 responden yang mengalami peningkatan pengetahuan. Walaupun demikian, hasil penelitian lain menunjukkan bahwa metode video animasi dapat meningkatkan pemahaman terhadap pengetahuan lebih baik dibandingkan video non animasi. $\underline{20}$

Disfungsi perkembangan akan menjadi kesulitan bagi anak tersebut dalam proses belajar dengan keterbatasan bahasa dan kosakata yang dimiliki anak tuna rungu sehingga berpengaruh terhadap tingkat intelegensi mereka. ${ }^{21}$ Faktor-faktor yang mempengaruhi proses belajar di atas menjadi faktor penghambat pada penelitian ini sehingga mempengaruhi hasil dan sulit untuk dikendalikan oleh peneliti. Durasi video animasi dengan pergantian teks dalam video dirasakan terlalu cepat sehingga anak tuna rungu sulit untuk mengikuti dan memahami informasi yang disampaikan dalam video animasi tersebut.

Aspek penting dalam pemberian penyuluhan pada anak tuna rungu dengan media visual maupun audiovisual yaitu berikaitan dengan isi (content) dan bentuk. Isi berhubungan dengan penempatan bagaimana rangkaian kata sebagai kerangka dasar ditempatkan dalam media yang digunakan dengan mempertimbangkan kemampuan anak tuna rungu dalam membaca. Bentuk berhubungan dengan aspek teknis seperti huruf, warna, dan penempatan dalam media yang digunakan.

\section{KESIMPULAN}

Kesimpulan penelitian menunjukan bahwa tidak terdapat perbedaan yang bermakna antara pemberian penyuluhan dengan metode komik dan video pada anak tuna rungu.

\section{UCAPAN TERIMA KASIH}

Peneliti mengucapkan terimakasih kepada guru, karyawan, orangtua, dan siswa di SLBN 1 Bantul atas kerjasamanya selama penelitian berlangsung. 


\section{DAFTAR PUSTAKA}

1. Laporan Hasil Riset Kesehatan Dasar (RISKESDAS) Nasional. Jakarta: Kementerian Kesehatan Republik Indonesia; 2013.

2. Profil Kesehatan Indonesia Tahun 2014. Jakarta: Kementerian Kesehatan Republik Indonesia; 2015.

3. Ramadhan A, Cholil C, Sukmana BI. Hubungan Tingkat Pengetahuan Kesehatan Gigi Dan Mulut Terhadap Angka Karies Gigi Di Smpn 1 Marabahan. Dentino J Kedokt Gigi. 2016;1(2):173-6.

4. Al-Darwish M. Oral Health Knowledge, Behaviour and Practices Among School Children in Qatar. Dent Res J (Isfahan). 2016;13(4):342.

5. K.K YIG, Pandelaki K, Mariati NW. Hubungan Pengetahuan Kebersihan Gigi dan Mulut dengan Status Kebersihan Gigi dan Mulut pada Siswa SMA Negeri 9 Manado. e-Gigi. 2013;1(2):84-8.

6. Rahayu C, Widiati S, Widyanti N. Hubungan antara Pengetahuan, Sikap, dan Perilaku terhadap Pemeliharaan Kebersihan Gigi dan Mulut dengan Status Kesehatan Periodontal Pra Lansia di Posbindu Kecamatan Indihiang Kota Tasikmalaya. Maj Kedokt Gigi Indones. 2014;21(1):27-32.

7. Gaçe E, Kelmend M, Fusha E. Oral Health Status of Children with Disability Living in Albania. Mater Sociomed. 2014;26(6):392-4.

8. Khursheed O, Gupta S, Singh C, Khursheed I, Bansal T. Assessment of Oral Hygiene Status and Prevalence of Dental Caries Among 3-14 Years Old Specially Abled Children Attending Various Special School in Mathura Distric, India. J Adv Med Dent Sci Res. 2015;3(1):33-9.

9. Dewi EN, Murdanu. Pengembangan Alat Peraga Materi Kelipatan Persekutuan Terkecil (KPK) Bagi Anak Tunarungu Kelas VII SLB Negeri 1 Bantul Tahun Ajaran 2015/2016. J
Pendidik Mat. 2017;6(3):9-20.

10. Zuraidah S, Syamsi K, Ashadi A. Improving The Story-Telling Skill of Grade 1 Students through The Use of Hand Puppet Media. J Prima Edukasia. 2020;8(2):166-76.

11. Yanti GN, Alamsyah RM, Natassa SE. Effectiveness of Dental Health Education using Cartoons Video Showing Method on Knowledge and Oral Hygiene of Deaf Children in Yayasan Karya Murni Medan. Int J Appl Dent Sci. 2017;3(2):86-90.

12. Selviana, Suwarni L. Promosi Kesehatan Melalui Media Film dalam Upaya Meningkatkan Perilaku Hidup Bersih dan Sehat Anak Sekolah Dasar Wilayah Pesisir Kepulauan. J Abdimas Mahakam. 2018;2(2):78-84.

13. Duncan R, Smith MJ. The Power of Comics: History, Form and Culture. New York: Continuum; 2009.

14. McNicol S. The Potential of Educatonal Comics as a Health Information Medium. Health Info Libr J. 2016;34(1):20-31.

15. Mutammam MB, Budiarto MT. Pemetaan Perkembangan Kognitif Piaget Siswa SMA Menggunakan Tes Operasi Logis (TOL) Piaget Ditinjau dari Perbedaan Jenis Kelamin. MATHEdunesa. 2013;2(2):1-6.

16. R MVA, AK AI, Firdausy MD. Hubungan Pengetahuan Kesehatan Gigi dengan Oral Hygiene Anak Tunarungu Usia Sekolah (Studi pada Anak Tunarungu Usia 7-12 tahun di SLB Kota Semarang). MEDALI J (Media Dent Intelekt. 2015;2(1):64-8.

17. Debrin N, Purwaningsih E, Soesilaningtyas. Efektivitas Penggunaan Media Flipchart dan Komik dalam Pendidikan Kesehatan terhadap Pengetahuan Menggosok Gigi pada Siswa SDI Raden Paku Surabaya. J Ilm Keperawatan Gigi. 2020;1(3):318. 
18. Saputro AD. Aplikasi Komik sebagai Media Pembelajaran. Muaddib. 2015;5(1):1-19.

19. Koutníková M. The Application of Comics in Science Education. Acta Educ Gen. 2017;7(3):88-98.

20. Sari RP, Elianora D, Bakar A. Perbandingan Efektivitas Penyuluhan dengan Video dan Animasi tentang Makanan Kariogenik terhadap Pengetahuan Siswa Kelas 4 di SDN 027Sungai Sapih Kec. Kuranji Padang. B-Dent J Kedokt Gigi Univ Baiturrahmah. 2017;4(2):117-25.
21. Rahman U. Karakteristik Perkembangan Anak Usia Dini. Lentera Pendidik J Ilmu Tarb dan Kegur. 2009;12(1):4657.

22. Adi PN. Pengembangan Audiovisual dalam Menerapkan Audiotory Verbal Therapy (AVT) pada Anak Tunarungu di Sekolah Inklusi PAUD Situbondo. Speed J Spec Educ. 2020;4(1):37-42. 